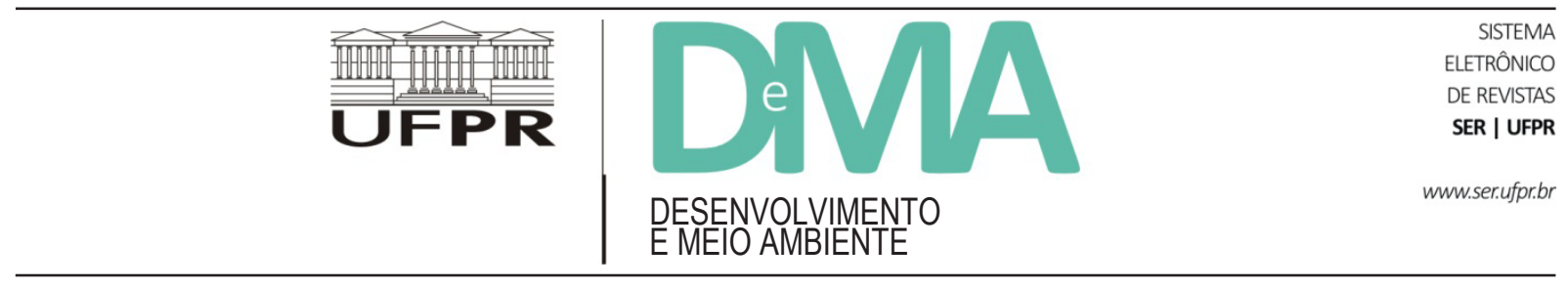

\title{
Depoimento de Claude Raynaut ${ }^{1}$
}

Minha decepção e meu pesar são imensos por não poder estar com vocês hoje para juntarmos nossos corações e dizer a nossa querida Magda o quanto ela permanece viva em nossa memória, em nossa vida.

Vinte e cinco anos de aventuras intelectuais compartilhadas, de fraternidade, de alegria e risos (a Magda tinha o segredo, até nos momentos mais tensos e difíceis, para combater a adversidade com risos). Vinte e cinco anos durante os quais ela se tornou um membro de minha família, pois ela não se satisfazia com uma simples parceria de trabalho e buscava sempre, além da relação de colaboração profissional, a própria pessoa humana na singularidade concreta de sua existência - sempre atenta a suas alegrias, penas, dificuldades e sucessos. Vinte e cinco anos compartilhados com a Magda representam então um monte de recordações nas quais as horas de exaltação intelectual, de mobilização em torno de convicções comuns se misturam com momentos de festa, de confidências a coração aberto.

Vinte e cinco anos: um quarto de século de amizade, de proximidade intelectual, de realizações comuns! Não é algo que possa esvanecer de vez apenas porque a pessoa se foi para outras ribas, desconhecidas. É matéria constitutiva de uma vida. Permanecerão vivos enquanto eu existir.

Inumeráveis são as facetas de uma personalidade tão rica e complexa como a de Magda. A imagem que surge depende de onde você está pensando, falando sobre ela. Existem tantas Magdas quanto pessoas que se relacionaram com ela, quanto circunstâncias e contextos dentro dos quais essas relações se deram.

Do lado do mar a partir do qual estou falando nela hoje, uma imagem se impõe a minha mente: a de uma mediatriz, uma passarela entre duas realidades sociais, duas culturas, a da França e a do Brasil. Pela sua própria história pessoal, ela mesma se forjou uma identidade híbrida: intimamente brasileira pelas experiências de sua infância e de sua mocidade, com seus engajamentos pessoais corajosos nos tempos da ditadura. Mas também profundamente francesa, após mais de quarenta anos de convivência com as realidades contraditórias desse país: desde a efervescência imaginativa dos anos pós-68 da qual participou ativamente, até a confrontação quotidiana com o mundo

\footnotetext{
${ }^{1}$ Antropólogo, foi Diretor de Pesquisa do CNRS - Centre national de la recherche scientifique (França) como Diretor do Laboratório de Pesquisa Santé, Sociétés, Développement da Universidade Bordeaux 2. É Doutor Honoris Causa da Universidade Federal do Paraná e conferencista da Escola de Altos Estudos da CAPES.
} 
acadêmico de nosso país, no qual ela aprendeu a desbravar seus caminhos com uma eficácia sem igual. Lançado mão de sua dupla experiência, de suas duas identidades, ela conseguiu então assumir um papel decisivo de intermediação entre a França e o Brasil.

A lista de suas iniciativas e de suas realizações nesse domínio não teria fim. Tantos alunos franceses vieram para o Brasil com uma bolsa do COFECUB obtida graças à participação ativa dela no comité de seleção. Alguns ficaram até hoje, outros se casaram com parceiros brasileiros, todos fizeram um trabalho excelente, um capital de conhecimento de primeira qualidade sobre o litoral paranaense.

Os doutorandos e pesquisadores brasileiros que vieram para França encontraram em Magda uma ajuda preciosa, tanto para resolver problemas quotidianos quanto para participar ativamente da vida intelectual parisiense nas Universidades, na Escola de Altos Estudos, no laboratório de pesquisa LADYSS do CNRS. Muitos são os eventos que ela organizou por aqui e por aí, onde se encontraram intelectuais e pesquisadores de ambos países.

Em termos institucionais, ela iniciou vários convênios entre universidades francesas e brasileiras no âmbito dos acordos entre a CAPES brasileira e o COFECUB francês: parcerias entre a Universidade de Paris 7 e de Bordeaux 2 por um lado e a UFPR e a UFPRGS, por outro.

Esse esforço sem descanso para promover e incentivar a colaboração entre intelectuais brasileiros e franceses estava a serviço de uma linha estratégica bem específica: juntar as forças para apoiar em bases científicas sólidas a formulação de políticas públicas alternativas para o desenvolvimento do mundo rural. Políticas atentas à valorização do papel que as sociedades rurais e a agricultura familiar podem desempenhar no futuro de nossos países, de nosso planeta.
Políticas que respeitem tanto os seres humanos na suas necessidades e aspirações quanto a natureza, da qual os pequenos agricultores foram os guardiões durante séculos. Essa estratégia científica não podia deixar de ser inovadora, em particular na necessidade de conjugar os olhares, as competências mais diversas, na exploração dessa temática: ecólogos, agrónomos, economistas, sociólogos, antropólogos e tantos outros.

No final dos anos oitenta, quando as evoluções políticas do Brasil permitiram a Magda voltar ao seu país natal, montar projetos de cooperação acadêmica baseados na colaboração de disciplinas diferentes era um objetivo inovador, tanto no contexto das universidades francesas como no das brasileiras. É aqui que ela teve uma intuição pioneira, cujas consequências prolongam-se até hoje. Para tratar tais problemas complexos e híbridos, era preciso montar um currículo de formação de alto nível para formar pesquisadores treinados a trabalhar numa perspectiva interdisciplinar. Ela encontrou no Paraná uma equipe de jovens docentes da UFPR que compartilharam com ela esse mesmo projeto: montar um doutorado interdisciplinar voltado para a temática do Desenvolvimento e do Meio Ambiente.

Foi nesse momento que, um pouco por acaso, a Magda e eu nos encontramos. Nessa época, no final dos anos oitenta, era eu um africanista inveterado com mais de vinte anos de pesquisa nesse continente - sem nunca pensar empreender qualquer trabalho no Brasil nem na América Latina. Mas já estava convencido da necessidade de adotar um enfoque interdisciplinar para tratar questões articulando dimensões materiais e técnicas com dimensões sociais e culturais: desafios do mundo contemporâneo ligados, entre outros, à exploração dos recursos naturais, ao crescimento urbano, à saúde das populações. Já 
tinha montado na África vários programas de pesquisa aplicando essa metodologia, mas sem nunca encontrar a possibilidade, no contexto da universidade francesa, de proporcionar um quadro institucional estável para a essa metodologia de pesquisa. Sem poder formar pesquisadores, teórica e praticamente, nessa perspectiva científica. As estruturas acadêmicas eram rígidas demais. $\mathrm{O}$ poder das disciplinas quase inabalável.

Magda me convidou para participar de seu projeto. Sua força de convicção, o entusiasmo dos pesquisadores curitibanos que encontrei quando ela me levou para lá, no início dos anos noventa, fizeram com que me apaixonasse por esse desafio. Outros vão contar melhor do que eu a história do Doutorado e o papel que teve a Magda no seu lançamento em 1994 e, em seguida, na sua consolidação dentro da instituição acadêmica brasileira e sua elevação ao estatuto de Cátedra UNESCO do Desenvolvimento Sustentável. Mas não posso deixar de destacar aqui o caráter quase profético da intuição de Magda: quando o Doutorado MADE foi criado, apenas um pequeno punhado de cursos de doutorado começavam a se engajar na aventura interdisciplinar - com destaque para o Núcleo de Altos Estudos Amazônicos em Belém e o Núcleo de Estudos e Pesquisas Ambientais em Campinas.

Hoje, as ideias pioneiras desses primeiros audaciosos programas tonaram-se um potente movimento, com amplas repercussões no nível mais alto da estrutura acadêmica brasileira - a CAPES - e com mais de duzentos diplomas interdisciplinares lançados em universidades distribuídas em todas as regiões do país. Nesses últimos vinte anos, o Brasil tem se tornado o mais brilhante exemplo dos sucessos de uma estratégia pública de incentivo e amparo dado às estruturas universitárias para responderem aos desafios contemporâneos da produção do conhecimento. A Magda foi uma das pouquíssimas faíscas que acenderam essa chama. O Doutorado MADE foi uma das pedras de fundação do edifício da interdisciplinaridade no Brasil.

Não poderia agradecer suficientemente à Magda por ter me trazido para o Brasil, por ter me associado à sua ousada aventura, dando-me assim a oportunidade de participar na concretização de ideias que não conseguiam ser postas em prática dentro do sistema acadêmico francês que, seja qual for sua excelência, carecia da flexibilidade e do espirito pioneiro que se encontravam nas universidades brasileiras.

Esses anos de participação na edificação das fundações do Doutorado, ao lado de nossas companheiras e nossos companheiros curitibanos, criaram entre mim e Magda uma fraternidade profunda. Não posso pensar sem imensa emoção nos nossos dois nomes gravados juntos na placa de inauguração da sede do Doutorado, nem na cerimônia em que nós dois recebemos o título de Doutor Honoris Causa da UFPR em 2004 - ano da celebração dos dez anos do MADE. Essas nossa convivência e cumplicidade não podem ser aniquiladas pela sua desaparição.

No Brasil, o Paraná foi apenas um dos muitos campos onde a Magda aplicou sua inextinguível energia, reunindo pessoas de ambos os lados do mar a serviço de um projeto comum: pesquisas, movimentos sociais, ações de desenvolvimento local. Todos esses empreendimentos seguiam uma linha estratégica comum: lançar pontes entre a produção do saber e sua utilização social. Ela me associou a alguns deles, no Rio Grande do Sul, no Amapá, recentemente em Pernambuco. Graças a ela, o Brasil ocupa uma posição de destaque na minha experiência intelectual e no meu coração. Isso para sempre, e de modo inseparável da pessoa, sempre viva, da Magda. 